\title{
Environmental assessment of proposed waste to energy plant for municipal solid waste for Thane Municipal Corporation, India
}

\author{
U. S. Kulkarni, H. T. Fendarkar \& K. M. Nair \\ M/s. Fine Envirotech Engineers, India
}

\begin{abstract}
The population in Thane city of Maharashtra in India is increasing rapidly and the subsequent increase in municipal solid waste (MSW) is creating issues in its collection, transport and treatment. Waste to energy (WtE) technology is one of the best techno-economically feasible technologies for treatment of MSW. This technology involves incinerating MSW in a controlled manner and the thermal energy thus produced is used to convert water into steam, which is then used to turn the turbines connected to generators that produce electrical energy. Economically, it will be a success as the project proposes to generate $10 \mathrm{MW}$ of electricity, conserving tons of non-renewable fuels. It not only reduces the volume of MSW by $90 \%$, but also produces non-conventional energy as a byproduct. Since this is a community project, an environmental impact assessment (EIA) has to be conducted in accordance with the Ministry of Environment and Forests (MoEF) guidelines. A baseline environment study (BES) was conducted by M/s. FEE in December 2013. Ambient air quality monitoring was carried out at six different locations depending on wind speed and direction, along with other important parameters such as water (surface and ground), noise, biodiversity and socio-economic aspects. All the parameters were found within advisory standards. EMP, DMP and risk assessments were designed and will be implemented accordingly. Based on the EIA, this $\mathrm{WtE}$ project would have major positive and very negligible negative impacts on the environmental parameters. The mitigating measures and monitoring plans have been formulated such that this project will be an economically and environmentally sustainable solution to dispose of the accumulating MSW and consequently generating clean energy. Keywords: municipal solid waste, waste to energy, environmental impact assessment, baseline environmental study, ambient air quality monitoring.
\end{abstract}




\section{Introduction}

India has one of the top ten highest economic growth rates and stands second in the world based on the population. Rapid industrialization and higher immigration rates to certain cities in India have led to consequent problems in these cities, such as lack of space, high cost of living, unemployment, etc. More and more dedicated departments in the Ministry of Government of India are solving these issues hand-in-hand with the growth and development. One such department is the Ministry of Environment and Forests with associated organizations like the Central Pollution Control Board, the Coastal Zone Management Authority, etc. One of the top problems arising out of the high immigration rate is the accumulation of high quantities of MSW. Like any other country before the innovation of waste management technologies, India also practised landfill as the most common method of waste disposal. But today the country recognizes the ill-effects of this practice and is adopting better technologies for disposing of the solid waste. The two main goals of an ideal technology would be reducing the volume of the waste generated to the minimum and recovering energy or useful by-products; at the same time having minimal or no negative effects on the environment. Such a step was initiated by Thane Municipal Corporation by proposing a project for development of a Waste to Energy Incineration plant in the city of Thane. Incineration technology has been under debate for a long time on environmental aspects due to two main reasons: reusable materials were lost in the process when unsorted waste was incinerated and the flue gas released due to combustion contained harmful constituents. Both these arguments against this technology have been taken care of by segregation of waste before incineration and improvement in the procedure to mitigate the emission of flue gases into the environment. It has been estimated that we can produce the same amount of energy from burning 3 tonnes of waste as from burning 1 tonne of oil (Renova [1]). It is considered today as one of the best ways to reduce greenhouse effects, climate change, etc.

\section{Project outline}

Thane city in Maharashtra, India is the north-eastern suburb at the head of Thane creek. It is a very fast developing city near Mumbai and hence attracts more and more migrations inward. The population of this city has been predicted to increase to double during the period from 2010 to 2031. Proportionately, it was predicted that the MSW generated per day on average will also increase. This MSW contains approximately $57.33 \%$ biodegradable components, $38.74 \%$ combustible components and $3.92 \%$ of inert components. The current systems for SWM do not meet the norms and guidelines and are not able to accommodate the increasing volume of MSW. TMC now requires an efficient technology that would reduce the volume of MSW with no negative effects on the environment and recover any useful by-product, if possible.

Currently, TMC has $96 \%$ efficiency for waste collection. TMC is employing measures like door-to-door collection, transportation vehicles carrying solid 
waste to the dumping areas, spraying deodorants and insecticides on the dumping grounds, etc. Open ground dumping is affecting the area around these grounds and also polluting the nearby water bodies. Present methods are not enough to handle the current generation of solid waste in the city; it will definitely not be able to accommodate the predicted increase in waste generation. The TMC is currently facing two problems: the high volume of MSW with not enough dumping grounds and the increasing negative impacts of this dumping on the environment. Thus, incineration technology was selected which will fulfil these needs by producing energy as a by-product.

\section{WtE technology}

Waste to Energy (WtE) basically involves the utilization of solid waste to recover energy that can be in the form of electricity, fuel or any other byproducts. Currently, there are about 2,500 incineration plants in the world (Avfall [2]). Typically it involves heating the solid waste at $1000^{\circ} \mathrm{C}$, while providing air for a controlled and efficient process of combustion. At these high temperatures, the waste burns automatically, without any provision of additional fuel. The high temperatures created inside the furnace converts the water in the pipeline network around the furnace into steam, which will turn the turbines and generate electricity at the rate of $10 \mathrm{MW}$ /day (as per the availability of MSW accumulated per day in this facility). This technology reduces the volume of the solid waste generated in the city and hence will conserve a huge chunk of landfill spaces. Also, it will allow the recovery of many useful products from the waste; which would otherwise be lost when directly dumped by landfill methods.

\section{Energy efficiency and recovery}

The technology of WtE will be optimized in such a way that the volume of landfill is reduced as much as possible, while having no negative impact on the environment and achieving maximum recovery of by-products and energy. Energy loss due to flue gases will be reduced. A boiler will be used to achieve $80 \%$ efficiency in thermal energy transfer. The electricity produced will be provided to the locals. Turbines and generators will be chosen in accordance with the type of MSW generated in the area (EC [3], FEA [4]).

\section{Emissions and residues}

The process at a typical WtE plant would have some residues and emissions that will have to be monitored and accordingly treated to avoid any harmful effects it may have on the environment. Also, some of these residues may be converted to useful by-products and utilized in various sectors of industries. Usually, a plant may give out some negligible air emissions, some liquid effluents and even some considerable amount of inert solid waste. Air emissions typically include particulate matter, sulfur and nitrogen oxides, carbon monoxide, acid gases, 
organic constituents, trace metals, dioxins, etc. Although a negligible and very small fraction of these are actually considered to be air pollutants at these concentrations, these parameters will have to be controlled and necessary mitigation measures will have to be taken. The potential sources of liquid effluents are air control equipment and any leachate from the waste. The amount and type of liquid effluent will depend on the type of air control system deployed as well as other design parameters of the plant. Solid waste is either formed during the sorting process before incineration or after the incineration process. This solid waste usually contains bottom ash, metallic scrap, air control system residues, activated carbon, etc.

\section{Management of residues and emissions}

Throughout the years, there have been many technological improvements in the design of a WtE plant. Today, it has been estimated that the air emissions typically released by a $\mathrm{WtE}$ plant are comparatively much lower than the heaters and fireplaces functioning in a typical household. Modern day WtE plants have air pollution control systems as an internal unit and hence release emissions that are undetectable (Stantec [8]). Also, with the increasing knowledge about the technology and the content of the MSW, the modern WtE plants have included operational controls that increase the efficiency of the process, thereby reducing any unwanted emissions or residues. To acquire a steady generation of energy, the MSW is constantly mixed before incineration to get a steady quality of waste and energy content. An adequate amount of air is made available during incineration to ensure a controlled and complete burning of the waste, thereby preventing the release of any unwanted by-products. Other modern day technologies include re-circulating part of the flue gas to reduce the production of $\mathrm{NO}_{\mathrm{x}}$ (Martin [5]), the use of electrostatic precipitators to reduce particulate matter, wet scrubbers or cleaners to settle heavy metals and acid gases, catalyzers to separate out dioxins, activated carbon adsorptions, fabric filter baghouses, etc.

\section{Regulations and EIA}

On 25th September, 2000, MoEF issued a notification called Municipal Solid Waste (Management and Handling) Rules, 2000. These regulations are now applicable to every governmental organization that is involved in collection, segregation, storage, transportation, processing, disposal, etc of municipal solid waste. These rules have been laid down specifically for different waste management technologies. Also, it specifically defines the desirable limits of environmental parameters that will have to be maintained during the entire process from collection to the post-disposal stages. For an incineration plant, operational standards and emission standards have been designed that need to be attained by the facility.

EIA is an important and comprehensive management tool that helps decision makers take appropriate actions concerning economic, technical and social as well as environmental aspects of the project. It is essential to include 
environmental impacts early into the project stages to avoid any negative impacts in the later stages of the project, which can be resolved early on (Alshuwaikhat et al. [9]). Especially in developing countries where the urban development and environmental sustainability have been planned separately, it has now been recognized by the authorities that these two components need to go hand-inhand. It is crucial to accomplish a balance between the two. For a proper sustainable development, even an environmentally friendly project needs to be assessed before its implementation. Hence, it is essential to carry out the environment impact assessment of the proposed project as well as the proposed site where the project will be established. As part of the EIA, the conditions currently prevailing at the site, the effects of the project implementation and any possible future implications due to the operation of the plant will have to be assessed and necessary decisions made before the project can take shape. Different criteria like economic impact, physical and chemical conditions of the site and the project, the flora and fauna and human reflections will have to be considered before project implementation.

\subsection{Screening and scoping}

This stage involved finding alternatives for the project site and analyzing the benefits and effects due to the development of the proposed project. In this case, the proposed site has been earmarked by the government for the ISWM plant. No other alternative sites were considered for this project. The type of waste generated in the city of Thane was also analyzed to understand the quality of the waste that can be used for clean energy production at the incineration plant. Considering the various benefits the city would have as a result of this project and because the plan adheres to the regulations set by the MoEF; the project was found to be a sustainable development in the city of Thane.

\subsection{Baseline environmental status}

This stage is where the proposed site is studied thoroughly; usually a $5 \mathrm{~km}$ radius around the site is taken into account. Various parameters like air, water, noise, socio-economic aspects, traffic, topography and geology, biodiversity, etc that forms the present conditions of the environment on-site are recorded. These studies along with the project plan; helps analyze the impacts the project might have on these parameters. In the case of this TMC incineration plant, the baseline values for all the parameters were found to be well within the limits set by MoEF and Maharashtra Pollution Control Board (MPCB). Traffic was found to be high during the day time around this area, owing to the fact that the bypasses beside this site connect busy industrial areas. Consequently, the air quality and noise levels were found to be a bit higher than expected, but still within desirable limits. The current status of the site was envisaged to be suitable for the proposed site. 


\subsection{Prediction of impacts and designing mitigation measures}

This stage is divided into two sub-stages. The first sub-stage involved analyzing the BES data and seeing if any of the values are beyond the limits. If they are, necessary mitigation measures will be designed for the same so as to bring those values within the limit. The second sub-stage is where the BES and the project plan are put together and impacts of the project on each of the parameters are predicted. Accordingly, mitigation measures are designed that will be implemented during all the affected phases of the project. This WtE plant site has moderate traffic and consequent issues which will be mitigated by arranging the transportation of the waste to the site during the night time, thereby having no effect on the BES. Due to the development of the project, no adverse impacts on the environment were envisaged. In spite of that, many mitigation measures were designed to either bring down the values of these parameters or to ensure the "zero-effect" on the environment.

\subsection{Environmental management plans}

EMP is a site specific plan developed to ensure that the project is implemented in an environmentally sustainable manner. EMP also ensures that the implementation is carried out in accordance with the design by taking appropriate mitigation measures to minimize impacts on the environment during both the construction and operational phase. EMP designed for this project includes the following actions:

- Designing mitigating measures for the abatement of undesirable impacts caused due to the project;

- Detailing of management plans;

- Setting up an Environmental Management Cell for the implementation of EMP along with an environmental officer to supervise;

- Setting up a post-project environmental monitoring program;

- Calculating the EMP costs to be included into the project capital amount (80 million INR during construction phase and 5.8 million INR/annum during operational phase).

Monitoring is an essential component for the sustainability of any developmental project. It is an integral part of any EIA. After recording the baseline data, predicting the impacts of the project and suggesting mitigating measures, it is mandatory to make sure that the project has monitoring plans to ensure the proper implementation of the designed measures. Also, although we have predicted the possible effects of the project, it is necessary to keep a constant check on certain parameters to ensure they stick to the values on the chart that we predicted. During the construction phase, these plans usually involve checking for appropriate permit, certificates and authorizations needed 
for each stage and also whether the project is complying with the EMP and governmental regulations. From the monitoring point of view, certain parameters are of the utmost importance like ambient air quality, water quality, noise levels, etc. These parameters will have to be monitored regularly based on the standard monthly/weekly/daily checklists for each. This record keepings and reporting would then be useful for the Environmental Management Cell to make any necessary changes in the EMP, if required.

\subsection{Risk analysis and disaster management plans}

Once a project is designed and we have the BES data, then there are impacts and issues that one can predict and necessary actions can be taken for the same. But, there can be many unpredicted incidents that may occur at the project site which has the potential to cause damage or loss of life and property. These sudden incidents or accidents that can occur at the project site are referred to as disasters, according to the MoEF. Recognizing these accidents, assessing the consequences of such accidents and designing a plan for such emergencies is called a DMP. The main objectives of this plan are to localize the emergency and if possible eliminate it and to minimize the effects of the incidents on people and property. It is necessary to assign responsibilities in such situations to certain people, so that there is a hierarchy of decision makers to take immediate action. These responsibilities not only include taking proper action during the emergency, but also ensuring the presence of proper emergency equipment onsite and the maintenance of post-disaster records and actions. The possible disasters are usually divided into two categories: natural and manmade. Each of these events is assessed separately and specific plans are made for each including the list of equipment to be available on-site, preparedness plans, responsible personnel, type of training, required contact details of the local authorities, etc.

\section{Continuous monitoring}

Monitoring at every stage of the process beginning from pre-construction stage is essential for not only ensuring that the development of this project would have no negative impact on the environment, but also to ensure that the ever-changing contents of the MSW in the area would not create any unpredictable impacts on the environment. This monitoring is also done as part of the EIA regulations to assure the MPCB that the project continues to be a sustainable one. This compliance monitoring is performed according to the standard daily/weekly /monthly/yearly charts for every parameter - air, water, noise, ecology, socioeconomic, etc. (Durham [7]).

\section{Management of WtE residues}

A typical WtE plant produces residues like bottom ash, fly ash, air pollution control residues, etc. Fly ash is either collected separately and transported to the brick factories for the manufacturing process or mixed with the air pollution 
control residues and treated collectively. Bottom ash refers to the solid waste generated post-combustion including ash, inert substances like glass, metals or rock, and carbon based partially burned by-products. Bottom ash will have to be screened electrically, magnetically or mechanically to recover the useful products before sending the inert useless residues for landfill. Air pollution control residues on the other hand are treated as hazardous waste and are treated according to the norms issued for the same (Algonquin [6]).

\section{Conclusion}

Incineration technology for the processing of MSW has been prevalent for many decades now. Many of these plants had to be shut down by the monitoring authorities or had to close down on their own. Initially, many plants were shut down because the technology failed to meet the desirable limitations set by the pollution control board. Improvements in technology successes to thwart these issues and are now able to satisfy the regulations issued by the MoEF. These improvements increased the operation cost of the facility. Because of this, many municipal authorities could not keep the plant running, just to incinerate the waste. They moved on to find better, yet cheaper technologies. But with the implementation of a $\mathrm{WtE}$ strategy into the incineration plant, this technology for disposal of MSW became feasible, from both environmental as well as economic perspectives.

In spite of having a sustainable technology for MSW disposal, it is still essential to carry out an impact assessment of the proposed project. Because, the type of technology adopted by a particular city will depend on the type of waste that it generates. An EIA of this type of ISWM project ensures that the technology is suitable for the city, has no adverse environmental impacts, will operate smoothly for a couple of decades, etc.

This case study about the Thane WtE incineration plant has been assessed from all these angles and has been found to be the best available technology for the city. This is one of the many incineration plants planned in the country. Establishment and operation of this plant would then launch many such WtE plants in the country thereby solving the problem of accumulation MSW in the entire country. This impact assessment would lay the base for all those upcoming incineration plants in India as well as any planned in other developing countries. In India, the ratio of population to available land for human activities is really high. Apart from solving the environmental issues caused by the accumulating MSW, it is equally essential to conserve the land spaces occupied today for landfills.

\section{Recommendations}

According to the impact assessment of this WtE plant, the project would be a good example of sustainable development in the city of Thane. With technological advances and better research on the MSW content, this technology would be improved further. But, although incineration is one of the top 
technologies to process MSW, it is recommended that this technology should not be implemented alone. It should preferably form a part of a chain of other technologies in an ISWM facility. It should be practised along with other approved technologies like a material recovery facility (MRF), refuse derived fuel (RDF), sanitary landfill (SLF), bioreactor landfill (BLF), composting, etc. This would ensure complete recovery of energy and byproducts from the waste that is generated in the respective cities. Apart from these, there should be more emphasis on the top two steps in the Waste Management Hierarchy - prevention of waste and reuse of the fractions.

\section{Abbreviations}

TMC - Thane Municipal Corporation

WtE - Waste to Energy

MSW - Municipal Solid Waste

FEE - M/s. Fine Envirotech Engineers

MoEF - Ministry of Environment and Forest

EIA - Environmental Impact Assessment

EMP - Environmental Management Plan

EMntP - Environmental Monitoring Plans

BES - Baseline Environmental Status

CPCB - Central Pollution Control Board

GoI - Government of India

SWM - Solid Waste Management

NOx - Nitrogen oxides

ISWM - Integrated Solid Waste Management

MPCB - Maharashtra Pollution Control Board

MRF - Material Recovery Facility

BLF - Bioreactor Landfill

SLF - Sanitary Landfill

\section{References}

[1] Renova., From waste to clean energy, Stromia-Futurum Grafiska AB, pg 9., 2010

[2] Avfall Svergie., Towards a greener future with Swedish Waste to Energy., pg 8., 2007

[3] EC (European Commission)., Integrated Pollution Prevention and Control: Reference Document on the Best Available Techniques for Waste Incineration., 2006

[4] FEA (Federal Environment Agency) - Austria. 2002. State of the Art for Waste Incineration Plants.

[5] Martin Gmbh fur Umwelt- und Energietechnik: http://www.martingmbh.de /index_en.php?level $=2 \&$ CatID $=6.79 \&$ inhalt $i d=66,2010$

[6] Algonquin Power Energy from Waste Facility Fact Sheet, http://www.peelregion.ca/pw/waste/facilities/algonquin-power.htm\#ash 
146 Environmental Impact II

[7] Durham/York Residual Waste Study Environmental Assessment, November 27, 2009, Stantec Consulting Ltd

[8] Stantec., Waste to energy: A Technical Review of Municipal Solid Waste Thermal Treatment Practices., pg6.02., 2011

[9] Alshuwaikhat H. et al., Int. J. Sus. Dev. Plann. Vol. 1, No. 2., pg 206., 2006 